\title{
The importance of titles
}

\author{
Karel Rakusan MD PhD
}

$I^{2}$ $\mathrm{n}$ this editorial, I do not mean to defend the titles belonging to the gentry or to various academic investigators. What I have in mind are the titles of an article or a book chapter.

The title is the most important part of any publication. Although they consist of short strings of words, or even of one word only, they may determine the whole fate of an article. Their choice reveals a degree of intellectual skill of the author and should be assigned with the greatest care. They must be brief. However, they should succinctly convey the message of the text that follows. In this respect I am reminded of a famous quote from Rousseau:

Excuse my long letter because I did not have enough time to compose a short one.

The title is the shortest version of your communication. Nevertheless, it should succinctly convey the message of the text that follows. We should keep in mind that the majority of your readers will read the title only.

Titles should contain only the essential message of the article. The following article, published recently in The Lancet, does not meet this criterion: "Trends in adult body-mass index in 200 countries from 1975 to 2014: a pooled analysis of 1968 population-based measurement studies with 19.2 million participants" (1). This title contains a list of numbers that are not extremely important. Is 200 countries very much different from 201? None of these five figures would help in information retrieval. It is, in my opinion, a reflection of a very large number of participants listed as coauthors.
Looking at my own list of publications, I am apprehensive about the following title: "Lognormal distribution of intercapillary distance in normal and hypertrophic rat heart as estimated by the method of concentric circles: Its effect on tissue oxygenation" (2). The title is too long and and leaves the reader with no clues regarding the key words. Besides, the method of concentric circles is now obsolete, being replaced by computer-generated tessellation. On the other hand, thirty years later, I still find the following title acceptable: "Protamine inhibits capillary formation in growing rat hearts" (3).

In conclusion, I propose the following two recommendations. First, try to eliminate all redundant expressions. Learn from the people in the advertising business, they carefully weigh every word because a client has to pay for it. For example, a 30-second commercial in the 2016 Super Bowl costed a cool $\$ 5$ million. That's an average of $\$ 167,000$ per second! Second, in contrast to the previous advice, try to include potential key words that your colleagues could use in an information retrieval search.

\section{REFERENCES}

1. NCD Risk Factor Collaboration Group. Trends in adult body-mass index in 200 countries from 1975 to 2014: A pooled analysis of 1968 population-based measurements studies with 19.2 million participants. Lancet 2016;387:1377-96.

2. Turek Z, Rakusan K. Lognormal distribution of intercapillary distance in normal and hypertrophic rat heart as estimated by the method of concentric circles: Its effect on tissue oxygenation. Pflugers Archiv 1981;391:17-21.

3. Rakusan K, Turek Z. Protamine inhibits capillary formation in growing rat hearts. Circulation Res 1986;57:393-8.

Department of Cellular and Molecular Medicine, University of Ottawa, Ottawa, Ontario

Correspondence: Dr Karel Rakusan, Department of Cellular and Molecular Medicine, University of Ottawa, 451 Smyth Road, Ottawa, Ontario K1H 8M5.

E-mail krakusan@uottawa.ca 